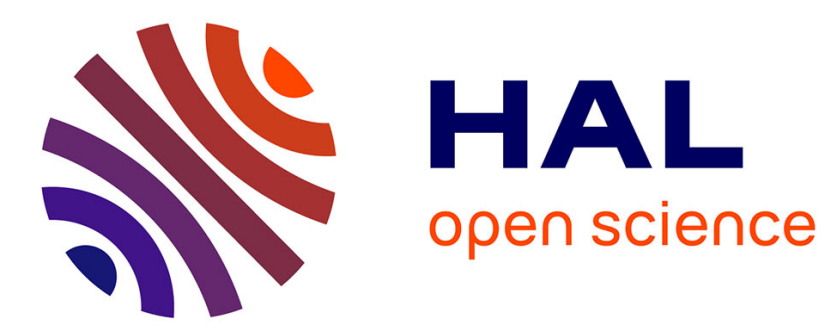

\title{
Presentation of KI-COF, a phenomenological model of variable friction in fretting contact
}

Mohammed Cheikh, Stéphane Quilici, Georges Cailletaud

\section{To cite this version:}

Mohammed Cheikh, Stéphane Quilici, Georges Cailletaud. Presentation of KI-COF, a phenomenological model of variable friction in fretting contact. Wear, 2007, 262 (7-8), pp.914-924. 10.1016/j.wear.2006.10.001 . hal-00134548

\section{HAL Id: hal-00134548 \\ https://hal.science/hal-00134548}

Submitted on 5 Mar 2007

HAL is a multi-disciplinary open access archive for the deposit and dissemination of scientific research documents, whether they are published or not. The documents may come from teaching and research institutions in France or abroad, or from public or private research centers.
L'archive ouverte pluridisciplinaire HAL, est destinée au dépôt et à la diffusion de documents scientifiques de niveau recherche, publiés ou non, émanant des établissements d'enseignement et de recherche français ou étrangers, des laboratoires publics ou privés. 


\title{
Presentation of KI-COF, a phenomenological model of variable friction in fretting contact
}

\author{
M. Cheikh ${ }^{1}$, \\ IUT de Figeac, avenue Nayrac F-46100 Figeac, France \\ S. Quilici G. Cailletaud \\ Centre des Matèriaux P.-M. Fourt, Ecole de Mines de Paris, UMR CNRS 7633, \\ BP 87 F-91003 Evry, France.
}

\begin{abstract}
In this paper, a new phenomenological model, called KI-COF is developed to account for variable coefficient of friction $(\mathrm{COF})$ in space and time. The $\mathrm{COF}$ is no longer considered as a global value valid for the whole contact area. A local value is introduced instead, the evolution of which is governed by the local history of the contact and the amount of slip.
\end{abstract}

Key words: Fretting wear, fretting fatigue, variable friction, coefficient of friction, contact.

\section{INTRODUCTION}

Fretting is the consequence of low oscillations between two bodies in contact [1]. The cycles can result from small relative displacements or stress variations in the bodies. It is most commonly found in all kinds of press fits, spline connections, leaf springs, riveted and bolted joints, nuclear fuel elements and also in wire ropes. The most significant factor in a contact with fretting is the coefficient of friction [2]. This factor is influenced by the surface quality, the wear induced by the fretting, the behavior of the third body, etc. Many studies have been completed for characterizing friction in fretting tests [2]. In the numerical studies dealing with fretting, the COF is generally presented as a constant of

$\overline{1}$ Corresponding author. E-mail: mcheikh@univ-tlse2.fr; Fax: +33 565503061 . Other address: Centre CROMeP, EMAC, Campus Jarlard - 81013 ALBI Cédex. 
the contact $[3,4]$. Actually, the COF varies according to the modification of the surface quality and the lubricant and it is never constant [5].

The present study is performed in connection with experiments made at 'Laboratoire de Tribologie et Dynamique des systèmes (LTDS)' of 'Ecole Centrale de Lyon' $[6,7]$ for characterizing the fretting behavior of a titanium alloy. Figure (1) presents the experimental apparatus used by Fridrici et al. [6]. It is composed of a cylinder, subjected to a normal load $\mathrm{P}$, sliding on a plane. The displacement amplitude $\delta$ is applied to the plane. In this test, the cylinder is coated and lubricated, the plane is shot peened without specific coating.

Figure (2) shows a typical evolution of the COF during a fretting test with a displacement amplitude of $\delta^{*}=50 \mu \mathrm{m}$. Each cycle of fretting represents the evolution of the ratio $Q / P$ according to displacement amplitude $\delta$ with $Q$ the tangential force. The COF $\mu$ is identified in the phase corresponding to the gross slip. By choosing the law of Coulomb $|Q| / P<=\mu$, the horizontal sides of these cycles represent the evolution of the $\mathrm{COF} \mu=|Q| / P$ according to displacement amplitude $\delta$. The near-vertical sides of the friction loops correspond to the sticking behavior. These sides are not completely vertical due to the flexibility of the plane-cylinder set. The slope of these sides corresponds to the rigidity of the contact between the plane and the cylinder.

This figure shows well that the coefficient of friction is variable in the interior of the cycles. It evolves with the amplitude and the direction of the slip. The COF also evolves with time while the fretting cycles number increases. The cycles have a parallelogram shape with horizontal sides for the first cycles. With the evolution of the fretting, these sides become oblique. The first cycles can be modeled with a constant $\mu$. The cycles with oblique sides cannot be modeled with a constant COF. To solve this problem, the numerical studies classically model this evolution by carrying out several calculations with different COF $[8,9]$. There is an absence of a friction model that can accurately simulate this temporal and spatial variations of the COF during fretting contact.

In this paper, a new phenomenological model, called KI-COF (Kinematic Isotropic coefficient Of Friction) is developed to account variable COF in space and time. The $\mathrm{COF}$ is no longer considered as a global value valid for the whole contact area. A local value is introduced instead, which evolution is governed by the local history of the contact and the amount of slip. The framework is inspired from elastoplasticity. The model presented in this study will allow us to derive a full modeling of the friction history during the whole life of the contact. The evolution of the COF depends on two variables: an isotropic evolution related to accumulated slip and a kinematic component computed from the actual relative position of the bodies. Other authors have already proposed an elastoplastic framework [10,11], nevertheless, to the best knowledge of the authors, the combination of an isotropic and a kinematic variable is original. 
Section 2 presents the elementary components of the friction model. Section 3 shows the finite element implementation of this model in the computer code ZéBuloN[12]. The last section presents the fretting cycles obtained by this model compared to those obtained by experiment in the case of cylinder-plane problem.

\section{DESCRIPTION OF THE MODEL}

In fretting contact, the increase of the roughness of contact surfaces with time is accompanied by a continuous evolution of the COF. This evolution is independent of the slip direction inside the cycles. This evolution represents the isotropic component of the COF. An evolution of $\mu$ versus slip is also found inside the cycles. The increase of slip is accompanied by an increase of the COF and the opposite slip is always facilitated compared to the current slip. This represents the kinematic component of the evolution of the COF. The kinematic evolution is the result of the degradation of the contact by abrasive wears, by the modification of the form of the contact surface, by the behavior of the third body, etc. The following section presents the evolution model of the isotropic and kinematic components of the COF.

\subsection{Modeling of the isotropic COF}

The isotropic COF $\mu_{\mathrm{R}}$ represents the expansion which the cycle of fretting undergoes with time. Between two cycles of fretting, $\mu_{\mathrm{R}}$ can be represented by the variation of the initial COF $\mu_{0}$ between these two cycles. For example, in figure (3), $\mu_{\mathrm{R} 1}$ represents the value of the isotropic component of the COF $\mu_{\mathrm{R}}$ after the first cycle. The isotropic COF is independent of the current slip direction $\delta$, it can thus be parameterized by a scalar variable like the energy of slip $\bar{E}_{\mathrm{d}}$ or the accumulated slip $\bar{\delta}$.

In this study we chose to model the isotropic $\mathrm{COF} \mu_{\mathrm{R}}$ according to accumulated slip $\mu_{\mathrm{R}}=f(\bar{\delta})$. Figure 4 presents some examples of the evolution of $\mu_{\mathrm{R}}$ according to accumulated slip. To model the experimental results of $\mu$, the function $f$ must have a nonlinear form in $\bar{\delta}$ and must have a threshold of saturation. The following form is used:

$$
\mu_{\mathrm{R}}=\mu_{1}\left(1-\exp \left(-b_{\mathrm{R}} \bar{\delta}\right)\right)
$$

with $\mu_{1}$ and $b_{\mathrm{R}}$ the parameters of the used material. The coefficient $\mu_{1}$ represents the threshold of saturation, hence the value of $\mu$ after saturation and $b_{\mathrm{R}}$ a 
factor of acceleration of the isotropic evolution of the COF. The accumulated slip is defined by

$$
\bar{\delta}(t)=\int_{0}^{t}|\dot{\delta}| d \tau
$$

with $\dot{\delta}$ the speed of the slip. Figure (4) presents the $\mu_{\mathrm{R}}$ obtained by this model with the experimental results.

\subsection{Modeling of the kinematic COF}

As mentioned above, the kinematic COF represents the component of the evolution of the COF dependent on the current slip $\delta$. For low values of $\mu$ the slip is generally full and the cycles have the shape of a parallelogram. Before the COF does not reach significant values, so that the slip is transformed into partial slip, the kinematic COF is linear in $\delta$ hence: $\mu_{\mathrm{X}}=H \delta$. For example, in the right curve of figure $3, \mu_{\mathrm{X} 1}$ represents the value of the kinematic $\mathrm{COF} \mu_{\mathrm{X}}$ at the end of the first alternation of the first cycle. The modulus $H$ represents the slope of slip. This modulus is generally variable and depends on accumulated slip $\bar{\delta}$ that is $H=g(\bar{\delta})$. The function $g$ represents the upward evolution of the slope in the phase of slip. If the modulus $H$ is constant, our model will be similar to the plastic model of Prager.

The experimental results show that the function $g$ must have a nonlinear form function of $\bar{\delta}$ and must have an asymptotic value after the saturation of the COF evolution. The function $g$ is modeled by:

$$
g(\bar{\delta})=\mu_{2}^{\prime}\left(1-\exp \left(-b_{\mathrm{X}} \bar{\delta}\right)^{\beta}\right)
$$

with $b_{\mathrm{X}}$ and $\beta$ the constants of fretting of the selected material. These two coefficients allow to adjust the acceleration of the kinematic evolution of the COF. The coefficient $\mu_{2}^{\prime}$ represents the slope value after saturation of evolution. This coefficient is not constant and depends on the maximum displacement amplitude of the test. Figure 5 presents two cycles obtained after saturation in two tests with displacement amplitudes of $\delta^{*}=50 \mu \mathrm{m}$ and $\delta^{*}=20 \mu \mathrm{m}$, for the first and the second test, respectively. The saturation slope for the first test is less significant than that of the second test with smaller displacement amplitude. This difference is explained by the fact that a small displacement amplitude is more favorable to the formation of a pad, which impedes slip and produces a sharp-pointed form of the cycle of fretting. This difference is also explained by the importance of the role of the displacement amplitude in the behavior 
of the third body in a contact with fretting. The slope at saturation evolves in the form of a reverse function $\mu_{2}^{\prime}=\mu_{2} / \delta_{\max }$ (see figure 6).

The kinematic COF takes then the following form:

$$
\mu_{\mathrm{X}}=\frac{\mu_{2}}{\delta_{\max }}\left(1-\exp \left(-b_{\mathrm{X}} \bar{\delta}\right)^{\beta}\right) \delta .
$$

with $\delta_{\max }$ represents the value of the displacement amplitude at the end of the alternation of the cycles. At the beginning of the slip for any alternation and at each change of the direction of slide, the kinematic COF $\mu_{\mathrm{X}}$ goes back to zero. For example, in figure 3 , at the points $\mathrm{A}$ and $\mathrm{B}$, the value of $\mu_{\mathrm{X}}$ is nil. Figure (7) represents some examples of evolution of

$$
\mu_{X \max }=\mu_{2}\left[1-\exp \left(-b_{\mathrm{X}} \bar{\delta}\right)^{\beta}\right]
$$

obtained by experiment and by the used model. $\mu_{\mathrm{Xmax}}$ represents the value of $\mu_{\mathrm{X}}$ at the end of the alternation of each cycle hence when $\delta=\delta_{\max }$.

\subsection{Modeling of the total COF}

The total COF $\mu$ is finally the sum of the kinematic component, the isotropic component and the initial $\mathrm{COF} \mu_{0}$ :

$$
\mu=\mu_{0}+\mu_{1}\left[1-\exp \left(-b_{\mathrm{R}} \bar{\delta}\right)\right]+\frac{\mu_{2}}{\delta_{\max }}\left[1-\exp \left(-b_{\mathrm{X}} \bar{\delta}\right)\right] \delta
$$

It is a model with 6 coefficients whose values depend on selected material. With this model, Coulomb law is introduced, so that:

$$
\begin{aligned}
& |Q|<=\mu P, \\
& \text { if }|Q|<\mu P \quad \text { stick, } \\
& \quad \text { if }|Q|=\mu P \quad \text { slip. }
\end{aligned}
$$

By choosing the variables $Q_{y}=\mu_{0} P, Q_{\mathrm{R}}=\mu_{\mathrm{R}} P$ and $Q_{\mathrm{X}}=\mu_{\mathrm{X}} P$, the law of Coulomb (7) takes the form of a yield function:

$$
f\left(Q, Q_{\mathrm{X}}, Q_{\mathrm{R}}\right)=\left|Q-Q_{\mathrm{X}}\right|-Q_{y}-Q_{\mathrm{R}},
$$

with $f<=0$ and the conditions $(8,9)$ become: 


$$
\begin{gathered}
\text { if } f<0 \quad \text { stick, } \\
\text { if } f=0 \quad \text { slip. }
\end{gathered}
$$

The KI-COF model (6) is general and can have simpler forms according to the conditions of fretting. The evolution of the COF depends on the coating and the lubricant. In the case of a coated and lubricated set, the evolution of the $\mathrm{COF}$ is progressive under the effect of the coating and the lubricant. The progressive damage of the lubricant is accompanied by a progressive increase in the COF. In this case the general form of the model (6) can be used. In the case of a cylinder without coating, the COF has a more significant value and almost constant along the test. In this case there is no isotropic evolution of the COF and the function $g$ (Eq. 3) is constant. Kinematic evolution depends only on the slip $\delta$. The model (6) takes a simpler form:

$$
\mu=H \delta
$$

similar to the linear kinematic model of Prager. The constant modulus $H$ represents the straight curve slope in the slip phase of the fretting cycle. In this case the cycles of fretting take the form of the right cycle of figure 3 .

\section{NUMERICAL IMPLEMENTATION}

This model applies locally in the contact area. In a finite element computation, for example, each element has its COF dependent on history, state of stress, slip, status of the contact zone, etc. This section describes the implementation of this model in the FE code ZéBuloN. To model the contact, ZéBuloN uses an impactor and a target. The impactor is composed of a set of nodes whereas the target is made up of a set of lines (or a set of faces for the 3D case). An element of contact is composed by a particle (a candidate node of the impactor) and the target. The initial COF $\mu_{0}$ and the other 5 constants of the model are global characteristics of the contact area. Each element of the contact zone inherits (in the meaning of object oriented programming) the same values of these constants. On the other hand, each element of contact has its accumulated slip $\bar{\delta}$ and its current slip $\delta$. Each element has thus, its kinematic component and its isotropic component of the COF.

\subsection{Identification of the model}

Figure (8) represents the identification method of the coefficients of the model. The coefficient $\mu_{0}$ is identified at the first cycle. It corresponds to the value 
of $Q / P$ at the point $\mathrm{A}$ or $\mathrm{B}$. The coefficient $\mu_{1}$ is identified at the saturation cycle. It corresponds to the $Q / P$ value at the point $\mathrm{C}$ of the saturation cycle. The coefficient $\mu_{2}$ is identified at the point D. It corresponds to the slope of saturation cycles. The coefficient $\delta_{\max }$ corresponds to the half alternation of the cycles.

The coefficient $b_{\mathrm{R}}$ represents the isotropic evolution which corresponds to the evolution between the points $\mathrm{A}$ and $\mathrm{C}$ in the figure. In the same way, $b_{\mathrm{X}}$ with $\beta$, represent the kinematic evolution which corresponds to the evolution from the point $\mathrm{B}$ to $\mathrm{D}$ in the figure. The identification in fretting of a material is carried out after a large number of cycles which can reach the million. In order to simulate numerically these tests with an acceptable computing time, an acceleration factor of the coefficients evolution of the model is used. In model (6) one replaces the coefficients $b_{\mathrm{R}}$ and $b_{\mathrm{X}}$ by respectively $b_{\mathrm{R}}^{\prime}$ and $b_{\mathrm{X}}^{\prime}$ with:

$$
b_{\mathrm{R}}^{\prime}=a b_{\mathrm{R}} \quad \text { and } \quad b_{\mathrm{X}}^{\prime}=a b_{\mathrm{X}}
$$

The coefficient $a$ is the acceleration factor of the model.

A second possible technique to accelerate calculation is the technique of cycle skip. Instead of modifying the coefficients $b_{\mathrm{R}}$ and $b_{\mathrm{X}}$, one increments periodically the value of accumulated slip. The coefficient $a$ in this technique represents the value of increment of the jump of cycle. Considering the weakness of displacement amplitude in front of accumulated slip, the two techniques are equivalent. In the applications presented thereafter the technique of acceleration is used.

\subsection{The contact algorithm}

To deal with the problems of contact ZéBulon uses a direct method known as method of flexibility $[13,14,15,16]$. With this method the conditions of contact are not introduced explicitly into the variational formulation of the problem. The reactions of contact are calculated a priori, then added in the equilibrium equations as known additional external forces in the deformed configuration $C^{t+\Delta t}$. The residual is then defined at time $t+\Delta t$ as:

$$
R^{t+\Delta t}=F_{\mathrm{int}}^{t+\Delta t}+F_{\mathrm{ext}}^{t+\Delta t}+R_{\mathrm{c}}^{t+\Delta t}=0
$$

$F_{\text {int }}$ and $F_{\text {ext }}$ respectively the internal and external forces. 
Displacements $u_{c}$ due to the contact are related to the contact reactions $r_{c}$ on a local frame of the element of contact by the relation

$$
u_{\mathrm{c}}=T^{\mathrm{T}} K^{-1} \operatorname{Tr}_{\mathrm{c}}=W r_{\mathrm{c}}
$$

with $W=T^{T} K^{-1} \operatorname{Tr}_{c}$ the matrix of flexibility condensed on the scale of the contact. The matrix $T$ is a linear operator allowing to express the local variables in the global frame such as $R_{c}=T r_{c}$. The system (16) represents the equilibrium system of the structure subjected to the contact reactions only. In order to define displacements $u_{c}$ and the reactions $r_{c}$, the law of Coulomb 7 and the condition of impenetrability (Signorini condition) are imposed.

Signorini condition is expressed by $r_{n}=\operatorname{Proj}_{\mathrm{R}^{+}}\left(r_{n}-\rho_{n} x_{n}\right)$ where $\operatorname{Proj}_{\mathrm{R}^{+}}$denotes the orthogonal projection on the positive real set $\mathbb{R}^{+} ; \rho_{n}>0$ and $x_{n}$ the gap between the particle and the target. The law of Coulomb can be expressed by: $r_{t}=\operatorname{Proj}_{C}\left(r_{t}-\rho_{t} \delta\right)$ where $\mathrm{C}$ is the disk $\left\{r_{t} \in \mathbb{R}^{2}:\left\|r_{t}\right\| \leq \mu r_{n}\right\}$ and $\rho_{t}>0$ [17]. To define the local unknown factors $\left(u_{c}, r_{c}\right)$ the following system is solved:

$$
\begin{aligned}
W r_{\mathrm{c}} & =u_{\mathrm{c}} \\
r_{n} & =\operatorname{Proj}_{\mathrm{R}^{+}}\left(r_{n}-\rho_{n} x_{n}\right), \quad \rho_{n}>0 \\
r_{t} & =\operatorname{Proj}_{C}\left(r_{t}-\rho_{t} \delta\right), \quad \rho_{t}>0 \\
\delta & =\delta_{\mathrm{lib}}+u_{\mathrm{ct}} \\
x_{n} & =x_{\mathrm{lib} n}+u_{\mathrm{c} n}+x_{n}^{0}
\end{aligned}
$$

with $x_{\text {libn }}$ and $\delta_{\text {lib }}$ respectively the gap and free slide when no contact reactions are applied and $x_{n}^{0}$ is the initial altitude of the particles. Once defined the local contact reactions $r_{c}$, one computes the global contact reactions $R_{c}=T r_{c}$ and solves the system (15).

\section{APPLICATION}

In order to validate the model, an application on the case of a cylinder-plane contact and a comparison with the experimental results of the LTDS are presented thereafter.

\subsection{Mesh and boundary conditions}

Figures (9) and (10) represent the mesh of the system. The influence of the size of the mesh on the developed model is checked by using two meshes (see figure 10): A coarse mesh with a typical element size of $50 \mu \mathrm{m} \times 25 \mu \mathrm{m}$ on the 
level of the contact, that is $1 / 10$ of the total contact area. And a finer mesh characterized by elements of $8 \mu \mathrm{m} \times 4 \mu \mathrm{m}$ in the contact area, that is about $1 / 64$ of the total contact area. First mesh allows a fast calculation of the cycles of fretting, whereas the second provides, in addition to the simulation of the cycles, a finer estimation of the local variables like stresses and strain in the contact area. This mesh is discreted with 1050 elements 2D with linear interpolation and 761 nodes, hence 1522 DOFs for the problem. For the second mesh, the set is discreted with 4744 elements 2D with linear interpolation and 3796 nodes, hence 7592 DOFs for the problem.

In experiments, at the beginning of each test, a vertical load $P$ is applied. The test is then continued by applying a cyclic displacement, with an amplitude of $\pm \delta^{*}$ to the plane (see figure 11). The normal load is applied to the cylinder in the form of an imposed displacement in order to reproduce the desired loading. This way of imposing the loading is in conformity with the tests performed at LTDS. In these tests, the imposed loading is not controlled and its value can vary during the test. The ends of the plane are constrained along the axis $\mathrm{y}$. The displacement amplitude $\delta(t)$ is applied to the plane along the $x$ axis. The higher extremity of the cylinder is constrained along the $x$ axis.

With the KI-COF model, it is not necessary to model the coating and/or the lubricant. The presence of the lubricant and the evolution of the contact with coating are taken into account indirectly by the evolution of the isotropic and kinematic hardening. In this study, the coating and lubricant are not represented.

Due to the small size of the contact area in front of the transverse dimension of the set, the mechanical behavior is supposed to be in plane deformation. A viscoplastic model with non linear isotropic and kinematic hardening is used $[18]$.

\subsection{Results}

In order to show the sensitivity of the KI-COF model to the smoothness of the mesh, all calculations were carried out by the two meshes presented on figure (10). The results of the calculations obtained by the two meshes are identical. Figure (12) represents a sample of fretting cycle obtained by the two meshes for a displacement amplitude $\delta^{*}=20 \mu \mathrm{m}$ and a loading $P=1000 \mathrm{~N}$. This figure shows well that the results of the two meshes are similar. In the following results the coarse mesh is used. Figure (13) presents the local evolution of the slip according to the cycles and the position $x$ of the contact nodes on the level of the interface cylinder-plane. This figure shows a fall of local slip with the cycles of fretting. The opposite phenomenon is observed on figure (14), with 
the evolution of the cycles the accumulated slip $\bar{\delta}$ increases. This increase of the accumulated slip is accompanied by an increase in the COF value as figure (15) shows it. Figures 13, 14 and 15 show for each cycle, in particular for the last cycles, that the local slip, the accumulated slip and the $\mathrm{COF} \mu$ are more significant at the end of the cylinder-plane interface than in the medium one.

Figures 16-18 present a sample of fretting test simulated by the suggested model with the coarse mesh in comparison with the corresponding experimental results. Figure 16 presents the results for a displacement amplitude $\delta^{*}=20 \mu \mathrm{m}$ and a loading $P=1000 \mathrm{~N}$. For the loading $P=400 \mathrm{~N}$, figures (17) and (18) present the results with displacement amplitude $\delta^{*}=25 \mu \mathrm{m}$ and $\delta=50 \mu \mathrm{m}$ respectively. The cycles with a legend $\mathrm{LN}$ represent the numerical cycles. The cycles with a legend LE represent the experimental cycles. For the experimental cycles the unit $K$ represents 1000 cycles. In each figure, the fretting $\log$ is presented with some samples of cycles representing the evolution of the COF according to time. Figure (16) shows that for the displacement amplitude $\delta^{*}=20 \mu \mathrm{m}$, the slip regime is mixed. The shape of the log is rectangular in the beginning which is the characteristic of gross slip, and at the end of the test the shape of the log becomes elliptic which is the characteristic of partial slip. Cycles presented in this figure show the same evolution for the experimental and simulated results. In this figure, until the 325000 th cycle, the cycles are parallelepipedic with sharp-pointed form at the end. After this cycle, the cycles become elliptic and the slip regime is partial. For the load $P=400 \mathrm{~N}$, the slip regime is gross for the displacement amplitude $\delta^{*}=25$ and $\delta^{*}=50$ as figures (17) and (18) show it. The fretting logs have parallelepipedic shape and the cycles keep a rectangular form along the test.

All the results presented in these figures demonstrate an acceptable agreement between the simulated evolution and the experimental cycles. The discrepancies between simulation and the experiment are due to the scatter in the experimental results as shown in figures ( 4 and 7 ), and pointed out by Friedrich $[7]$.

\section{Conclusion}

In this paper, we proposed a model of evolution of coefficient of friction in fretting contact. This model was implemented in a finite element code. A constitutive equation is defined to predict the evolution of the coefficient of friction. The proposed rule, called the KI-COF model, introduces both an isotropic evolution and a kinematic evolution if the COF. Using this model, the COF is no longer uniform: in a FE computation, one defines a field of $\mathrm{COF}$, which depends on each point of the local history of the contact. The agreement between the numerical simulations and the experimental results is 
encouraging. The generalization of the model to the 3D case requires the use of an anisotropic model of friction: the kinematic variable will become a tensor, meanwhile the isotropic one will remain scalar.

\section{Acknowledgments}

This study is financially supported by SNECMA Moteurs. The authors wish to thank P. Perruchaut and S. Mosset (from SNECMA Moteurs-Villaroche) for the helpful discussion and permission to publish. The authors are grateful to V. Fridrici and S. Fouvry (from LTDS, Ecole Centrale DE Lyon) for providing experimental data and for fruitful discussions.

\section{References}

[1] R. B. Waterhouse. Fretting fatigue. Inter. Materials Reviews, 37(2):77-97, 1992.

[2] M. P. Szolwinski and T. N. Farris. An experimental study of fretting fatigue crack nucleation in airframe alloys: a life prediction and maintenance perspective. In Proceedings of 1 st joint DoD/FAA/NASA conference on aging airfact, Ogden, UT, 1997.

[3] N. Strömberg. A Newton method for three-dimensional fretting problems. Int. J. Solids and Structures, 36:2075-2090, 1999.

[4] C. Petiot, L. Vincent, K. Dang Van, N. Maouche, J. Foulquier, and B. Journet. An analysis of fretting-fatigue failure combined with numerical calculations to predict crack nucleation. Wear, 181-183:101-111, 1995.

[5] D. R. Swalla and R. W. Neu. Influence of coefficient of friction on fretting fatigue crack nucluation prediction. Tribology international, 34:493-503, 2001.

[6] V. Fridrici, S. Fouvry, and P. Kapsa. Effect of shot peening on the fretting wear of Ti-6Al-4V. Wear, 250:642-649, 2001.

[7] V. Fridrici. Etude du comportement en fretting d'un alliage de titane Ti-6Al$4 \mathrm{v}$ : Application au dimensionnement du contact aubedisque de fan. Thèse d'université, École Centrale de Lyon, 2002.

[8] A. E. Giannakopoulos and S. Suresh. A three-dimesional analysis of fretting fatigue. Acta mater., 46(1):177-192, 1997.

[9] C. T. Tsai and S. Mall. Elasto-plastic finite element analysis of fretting stresses in pre-stressed stip in contact with cylindrical pad. Finite elements in analysis and design, 36:171-187, 2000. 
[10] A. Curnier. A theory of friction. Int. J. Solids Structures, 20(7):637-647, 1983.

[11] R. Michalowski and Z. Mroz. Associated and non-associated sliding rules in contact friction problems. Arch. Mech., 30:259-276, 1978.

[12] Zebulon. A finit element code. See www.nwumerics.com for more information.

[13] A. Francavilla and O. C. Zienkiewicz. A note on numerical computation of elastic contact problems. Int. J. Numer. Methods Eng., 9(4):913-924, 1975.

[14] T. D. Sachdeva and C. V. Ramakrishnan. A finite element solution for the twodimensional elastic contact problems with frictions. Int. J. Numer. Methods Eng., 17:1257-1271, 1981.

[15] M. Jean and G. Touzot. Implementation of unilateral contact and dry friction in computer codes dealing with large deformations problems. Journal de Mécanique théorique et appliquée, 7(supplement n: 1):145-160, 1988.

[16] M. Wronski. Couplage du contact et du frottement avec la mécanique non linéaire des solides en grandes déformations. Thèse d'université, Université de Technologie de Compiègne, 1994.

[17] F. Jourdan, P. Alart, and M. Jean. A gauss-seidel like algorithm to solve frictional contact problems. Computer Methods in Applied Mechanics and Engineering, 155:31-47, 1998.

[18] J. Lemaitre and J.-L. Chaboche. Mécanique des matériaux solides. Dunod, Paris, 1988. $2^{e}$ édition. 


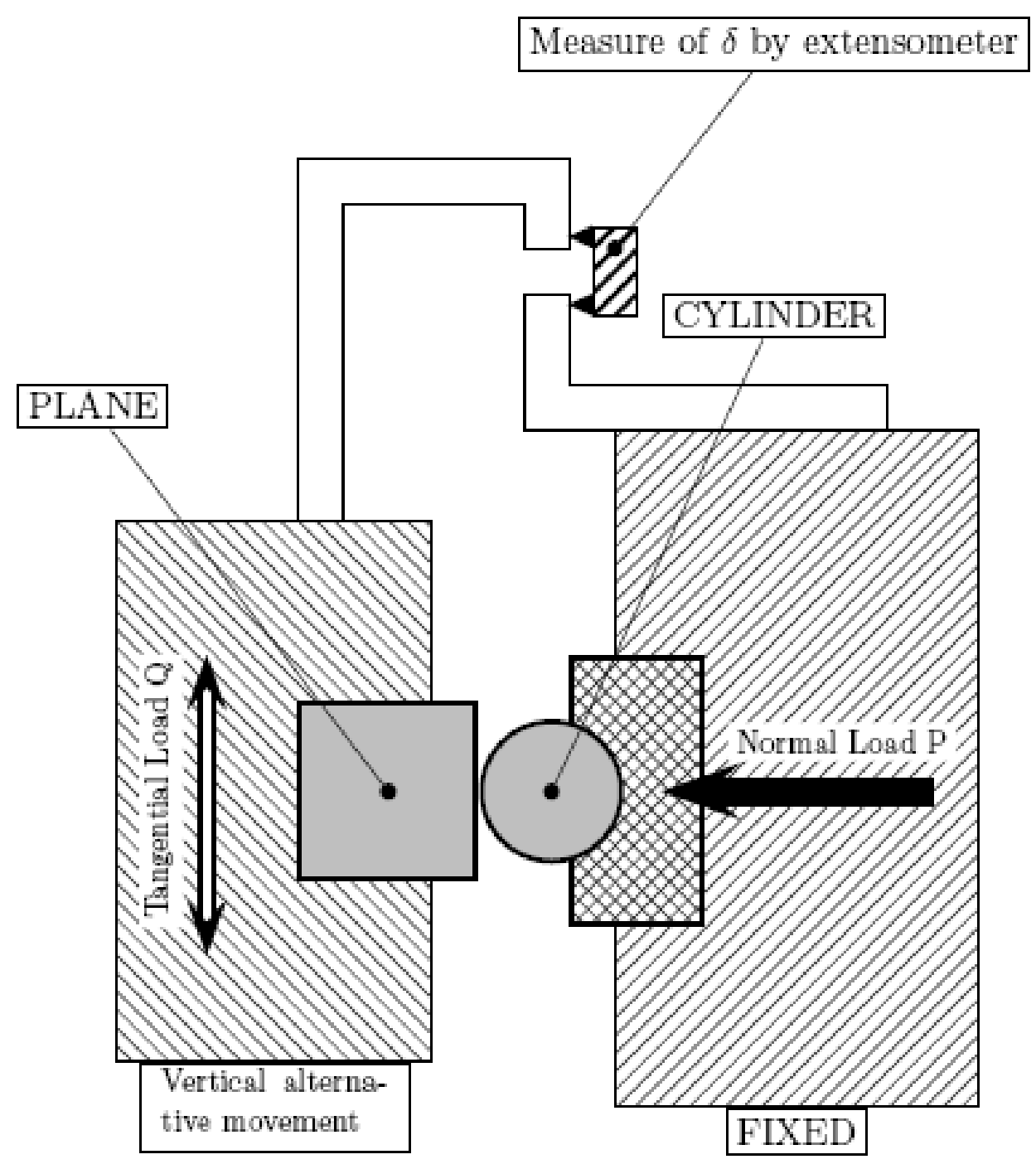

Figure 1. Experimental apparatus of the plane-cylinder. 


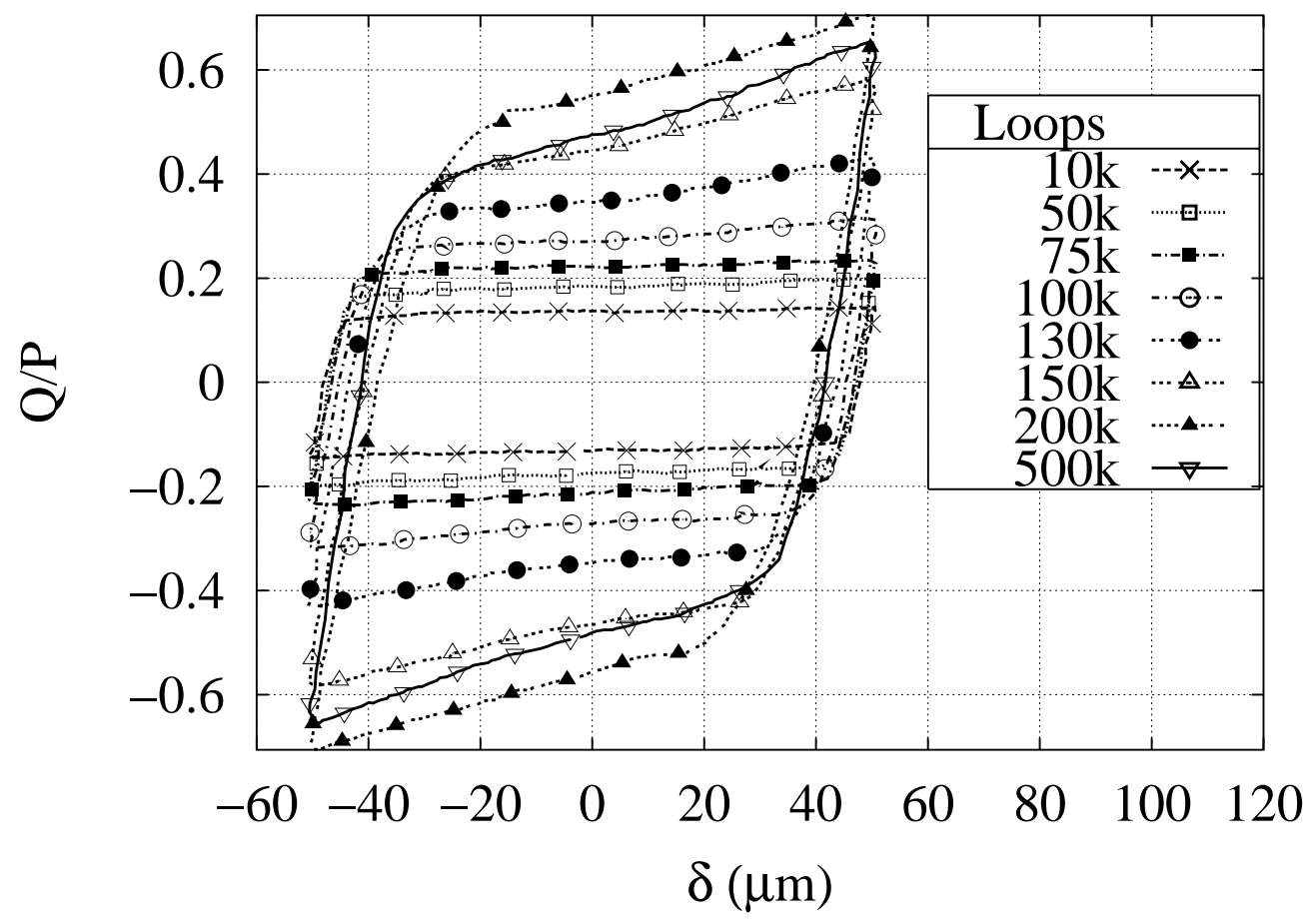

Figure 2. Examples of fretting cycles for $\delta^{*}=50 \mu \mathrm{m}$. The unit $\mathrm{k}$ represents 1000 cycles [7]. 

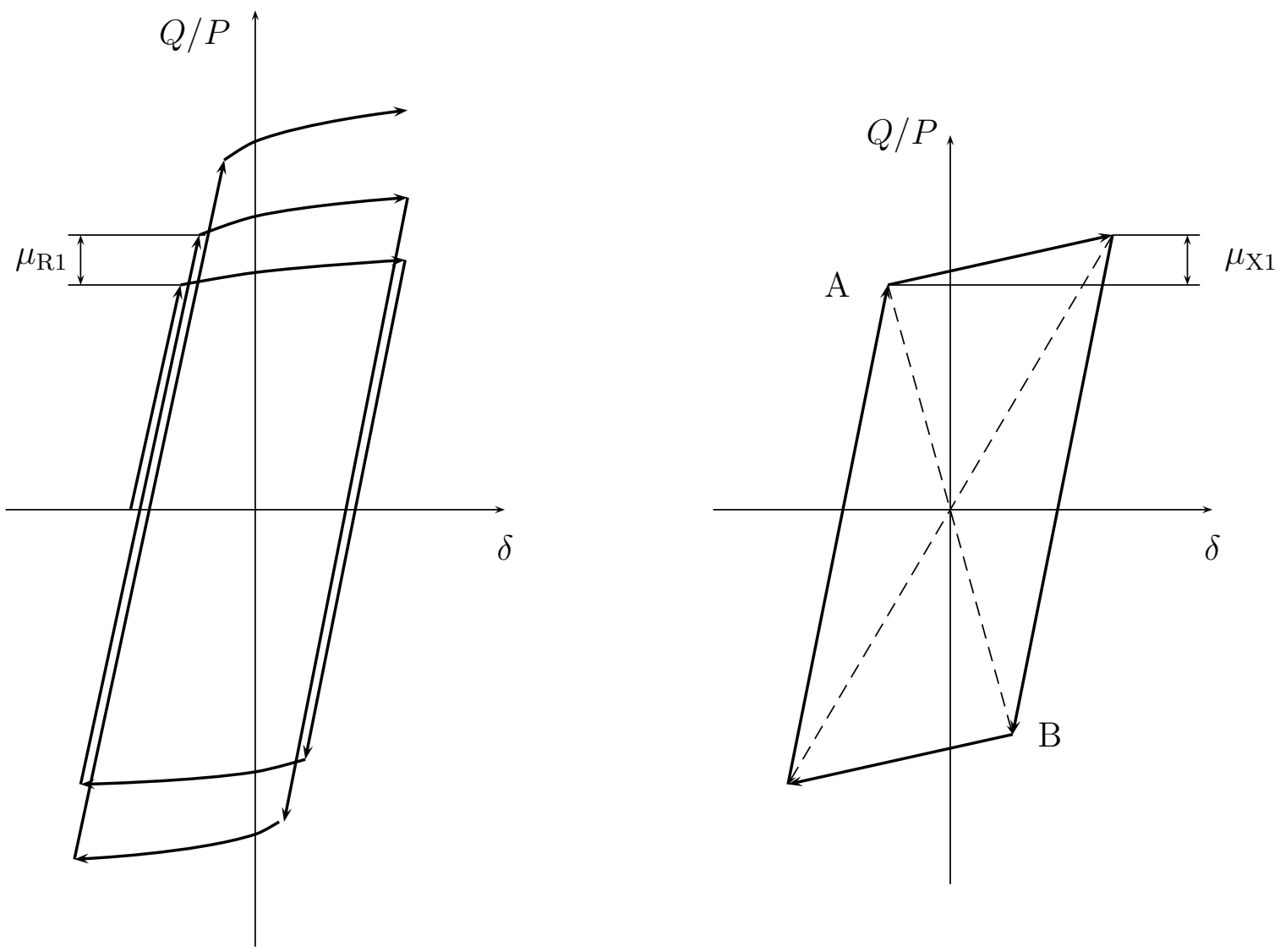

Figure 3. Definition of the kinematic component and the isotropic component of the COF. The left curve represents the isotropic evolution only (the kinematic evolution is neglected) and the right curve represents the kinematic evolution only (the isotropic evolution is neglected). 


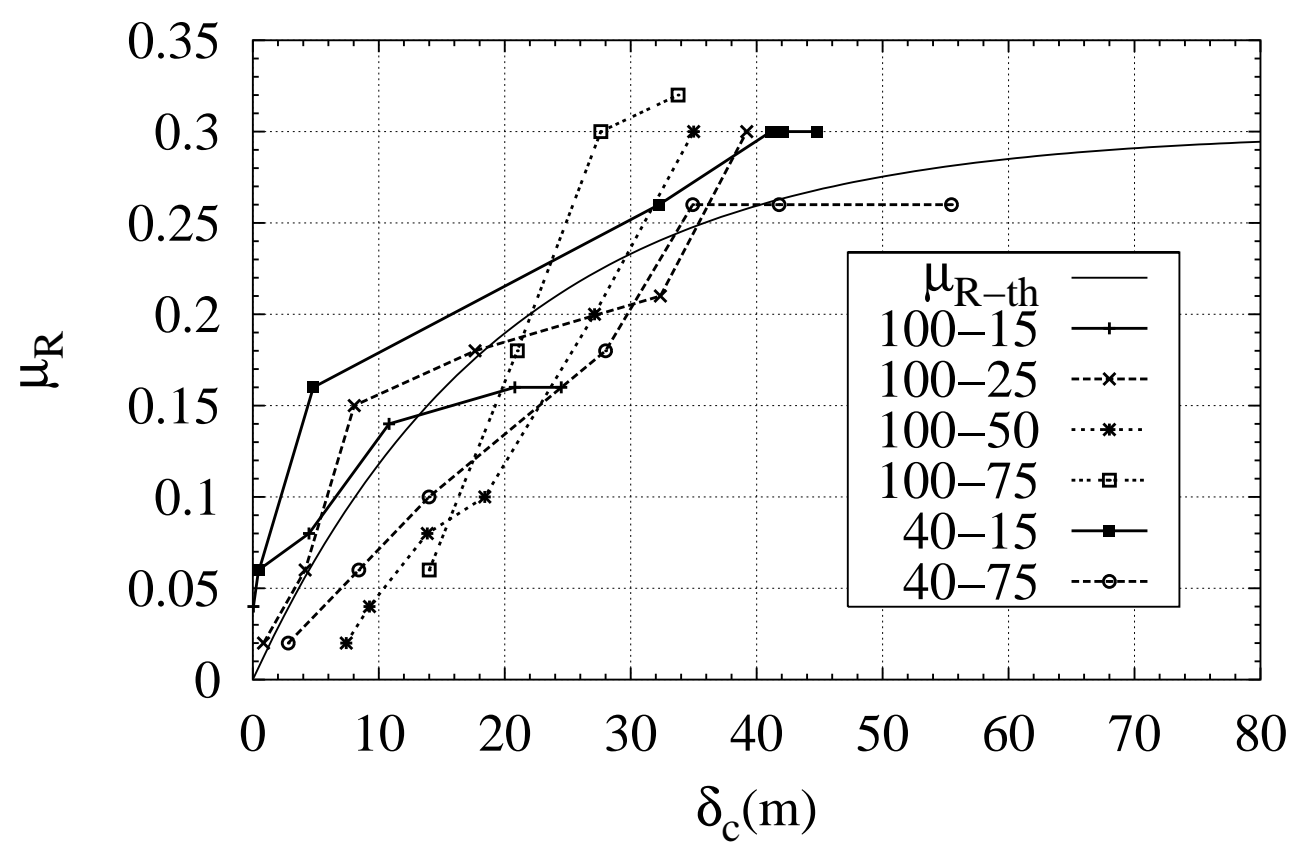

Figure 4. Examples of evolution of the isotropic component of the COF $\mu_{\mathrm{R}}$ according to the accumulated slip $\delta_{\mathrm{c}}=\bar{\delta}$ (in meters) obtained by the experiment. The first number of every legend represents the loading, the second represents the imposed displacement. $\mu_{\mathrm{R}-\mathrm{th}}$ represents the evolution of $\mu_{\mathrm{R}}$ obtained by our model (Eq. 1) 
(a)

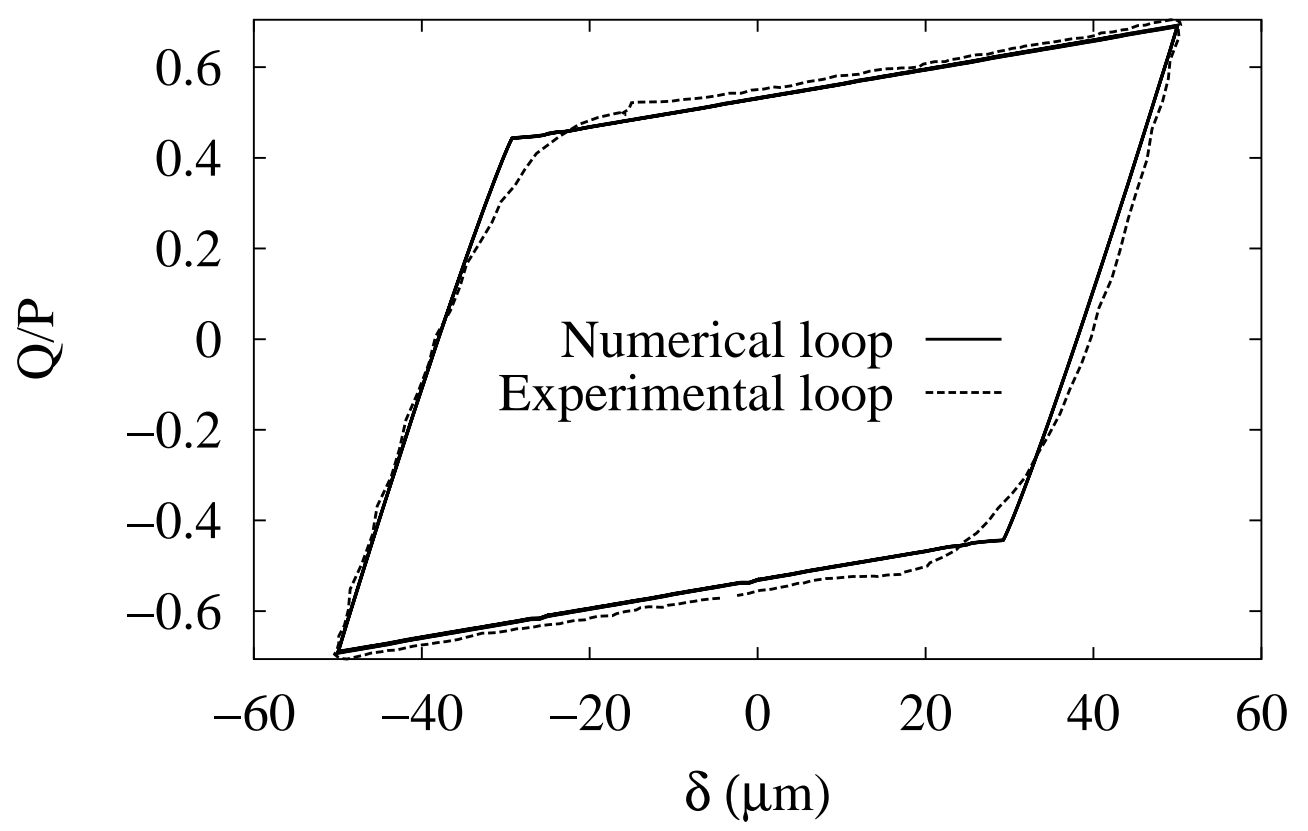

(b)

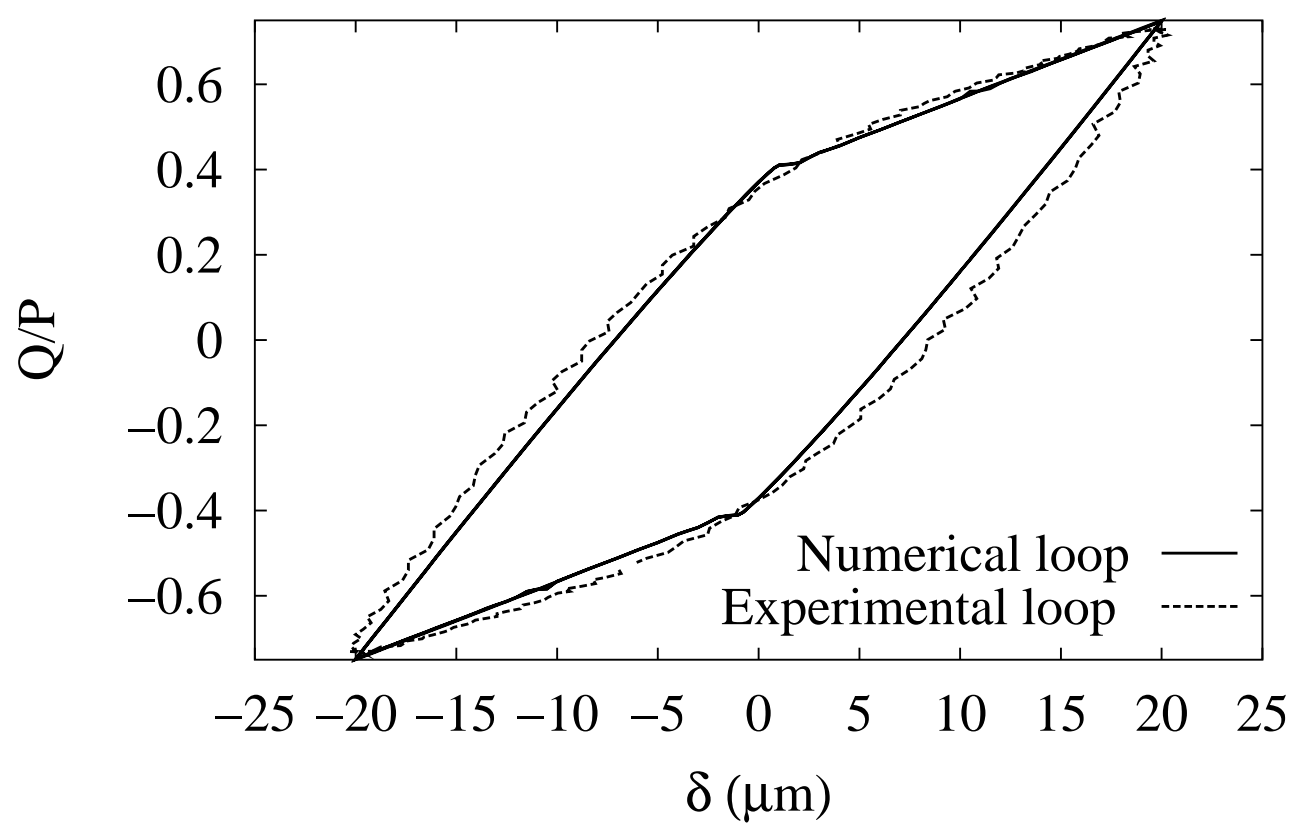

Figure 5. The displacement amplitude influence on the slope form of the saturation cycle: The slope of the cycle with $\delta^{*}=20 \mu \mathrm{m}$ (case b) is more pronounced than the cycle with $\delta^{*}=50 \mu \mathrm{m}$ (case a). 


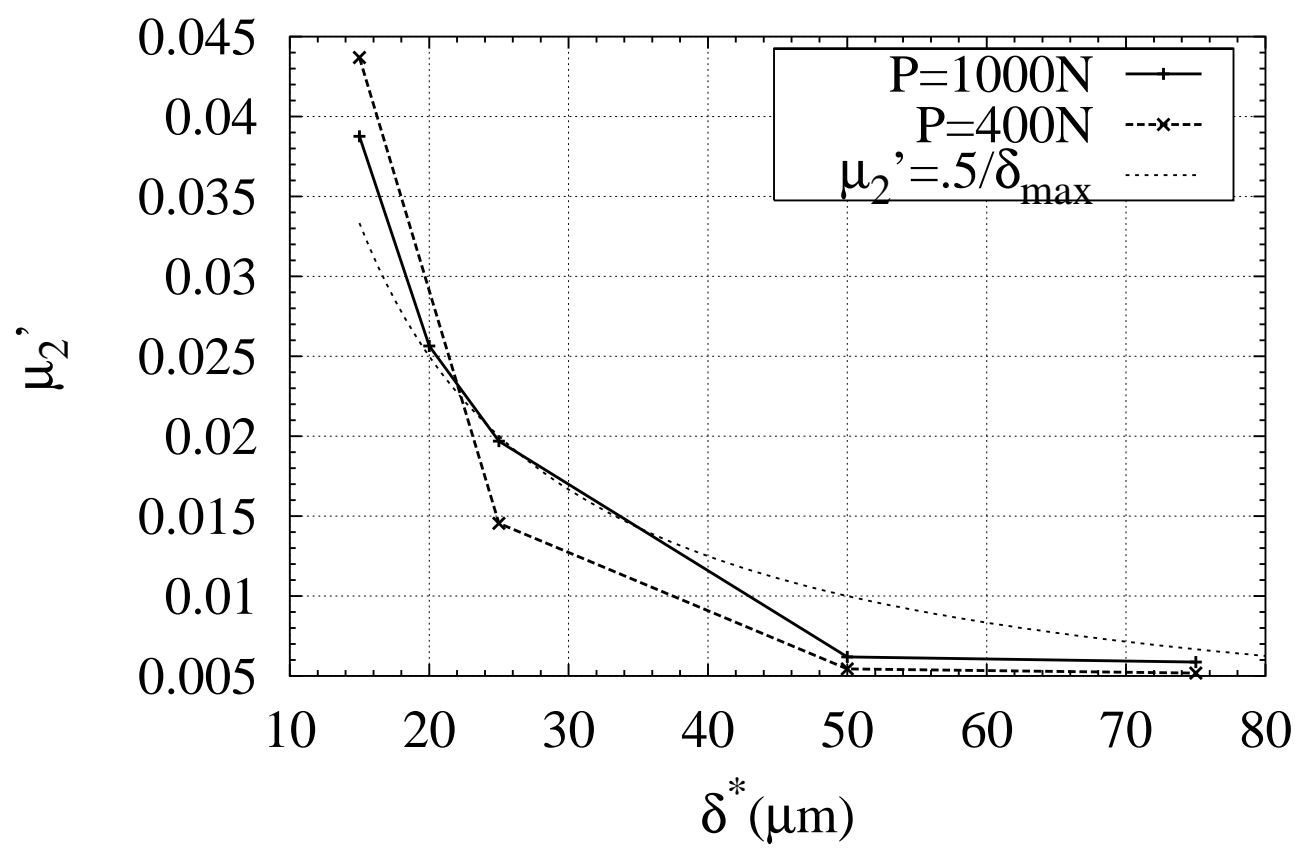

Figure 6. Evolution of the slope after saturation for the loadings $\mathrm{P}=1000 \mathrm{~N}$ and $\mathrm{P}=400 \mathrm{~N}$ and for the theoretical value with $\mu_{2}=0.5$. 


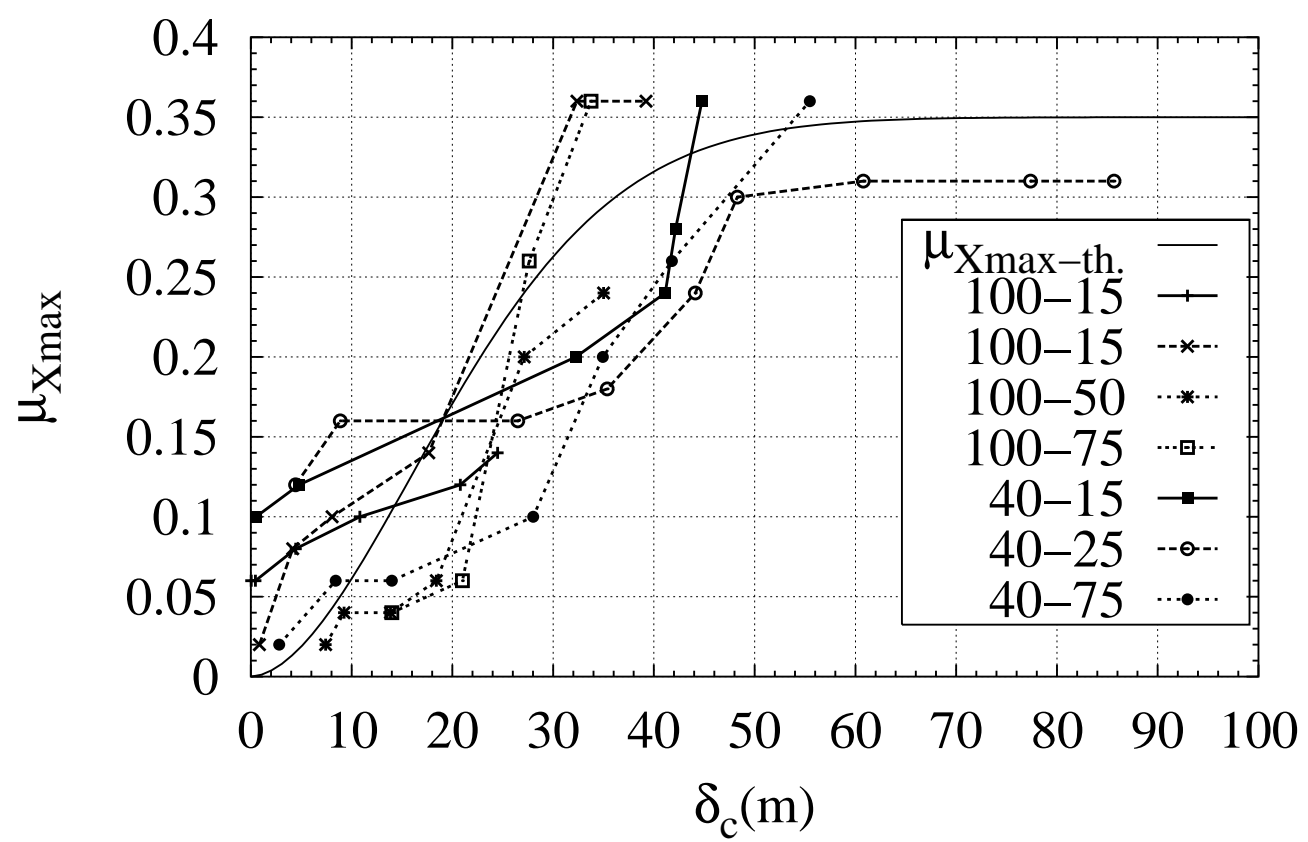

Figure 7. Examples of evolution of $\mu_{\text {Xmax }}$ according to the accumulated slip $\delta_{\mathrm{c}}=\bar{\delta}$ (in meters) obtained by experiment. The first number of every legend represents the loading, the second represents the imposed displacement. $\mu_{\mathrm{X}-\text { th }}$ represents the evolution of $\mu_{\text {Xmax }}$ obtained by our model (Eq. 5) 


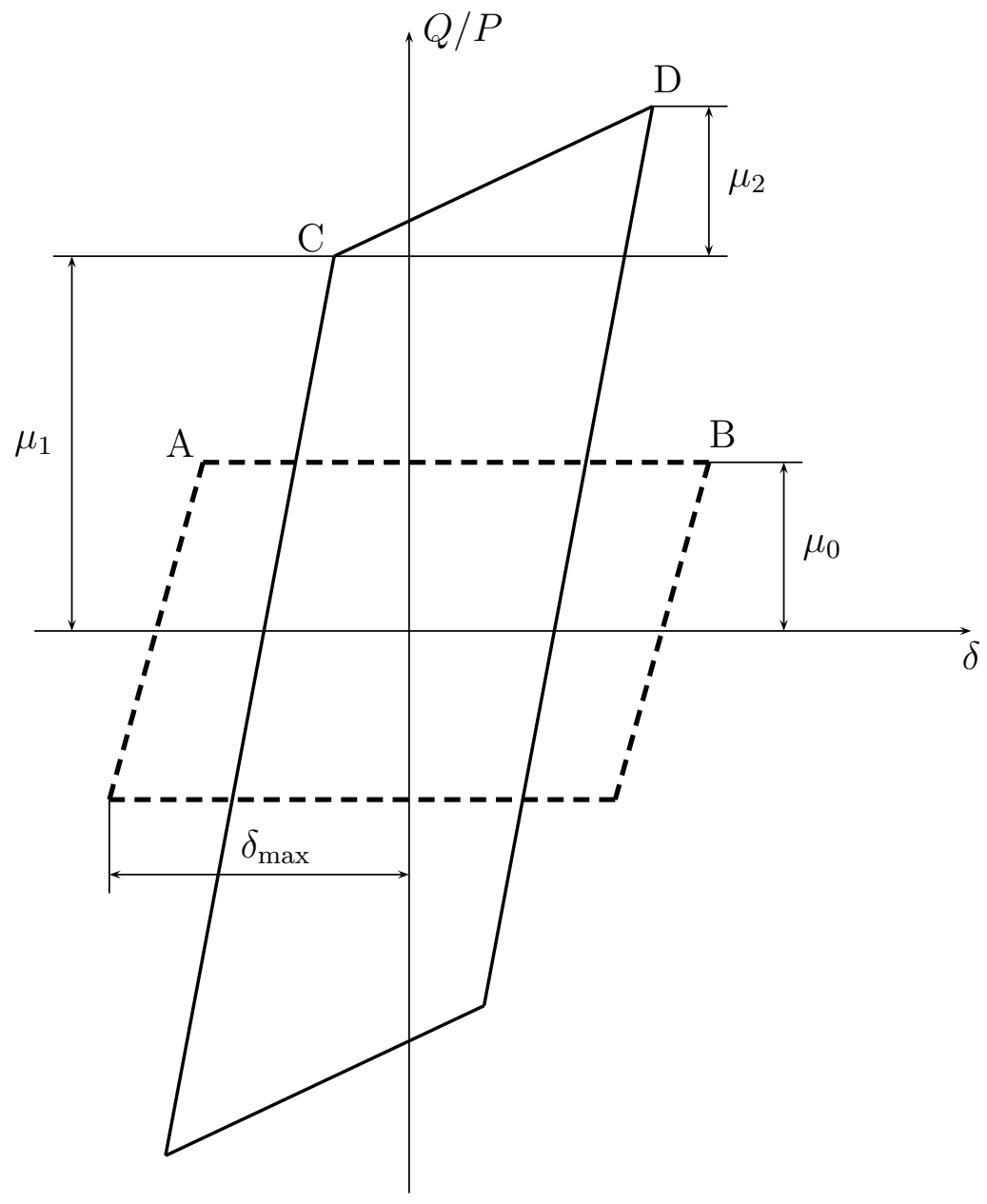

Figure 8. Identification of the different coefficients of the model. The dashed cycle represents the first cycle and the other cycle represents the saturation one. 


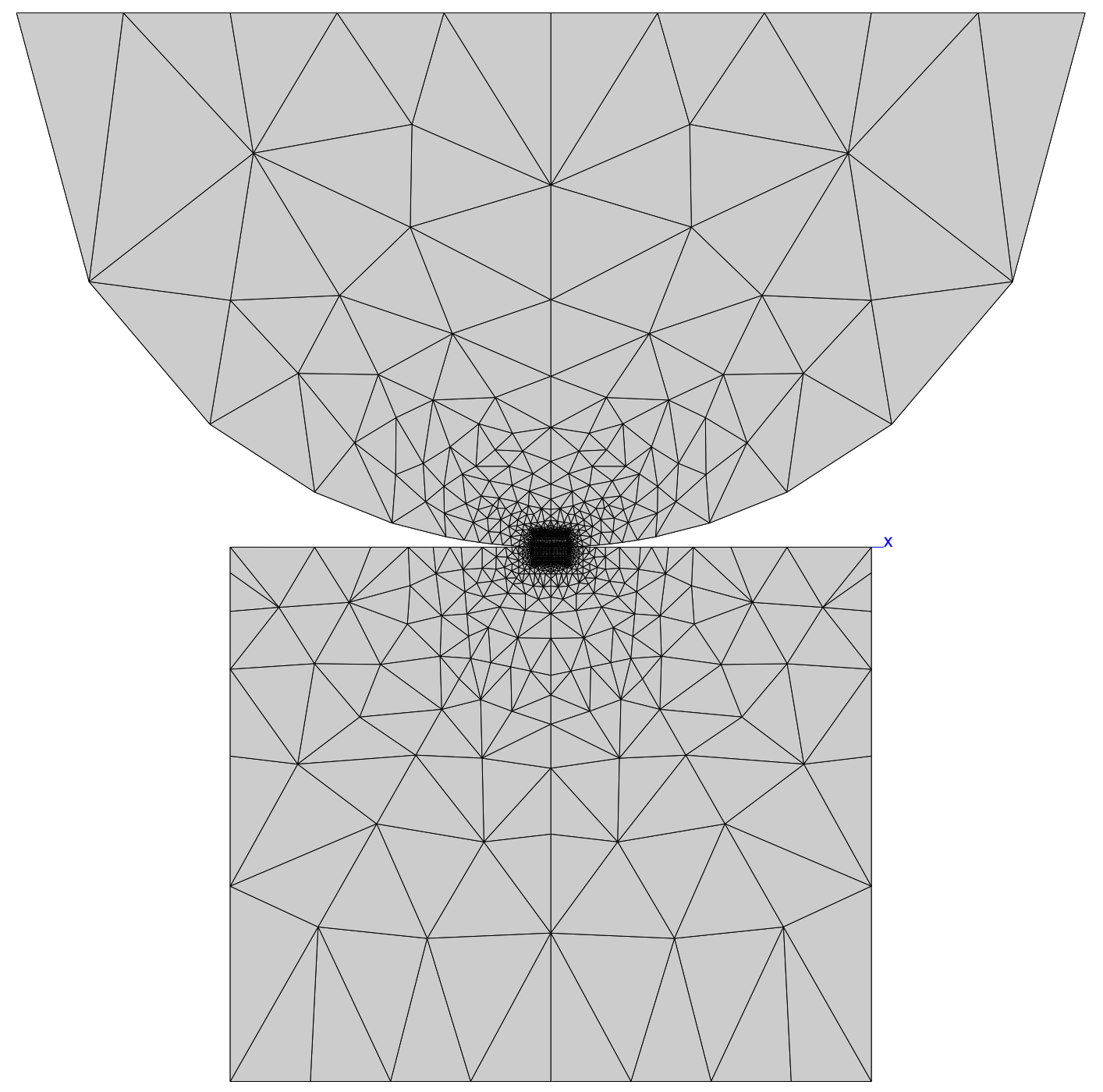

Figure 9. Cylinder-plane set mesh 
(a)

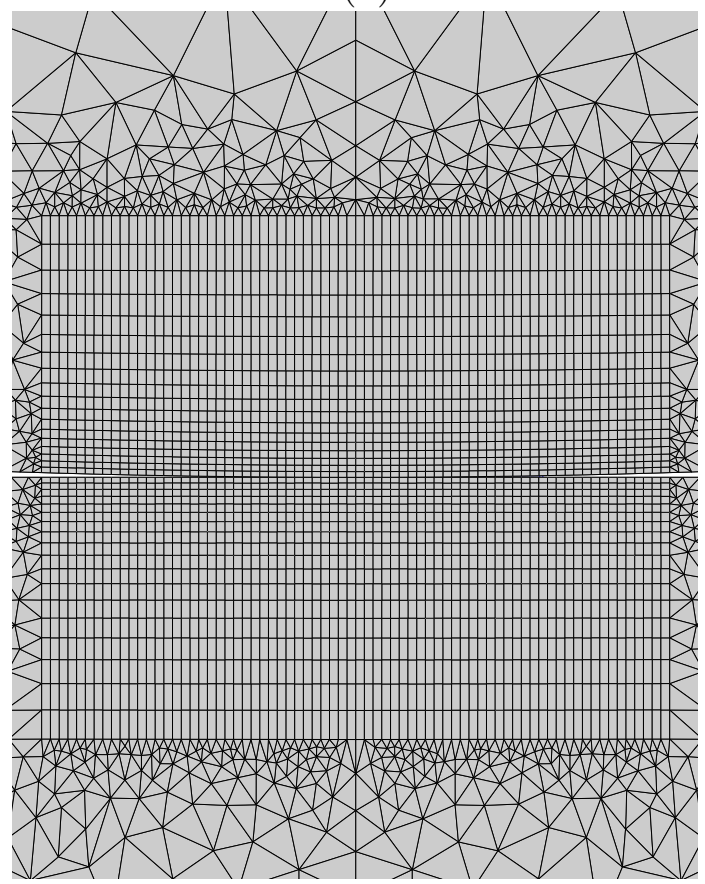

(b)

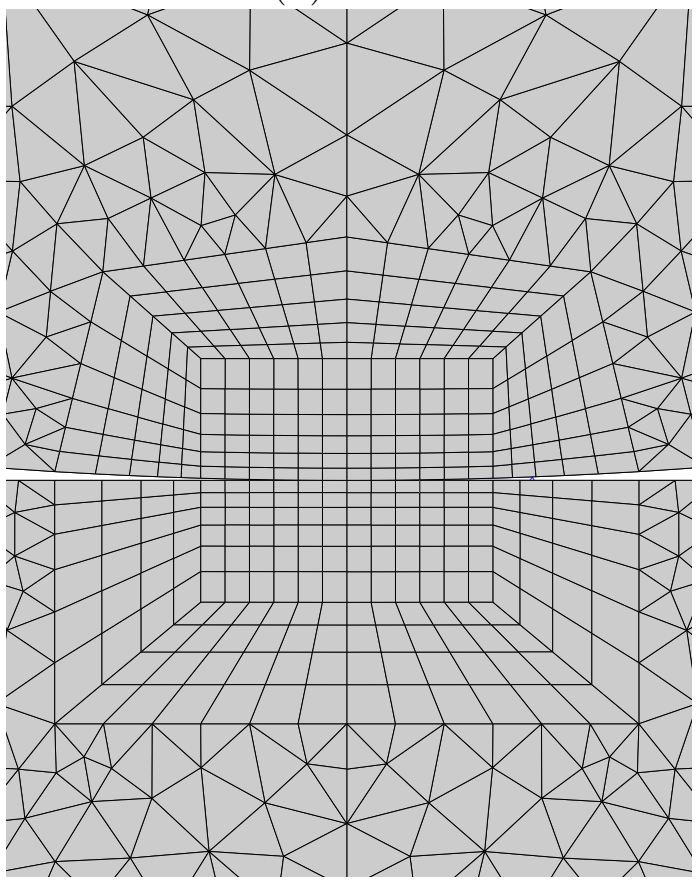

Figure 10. Zoom of the contact zone : a) finer mesh; b) coarse mesh. 


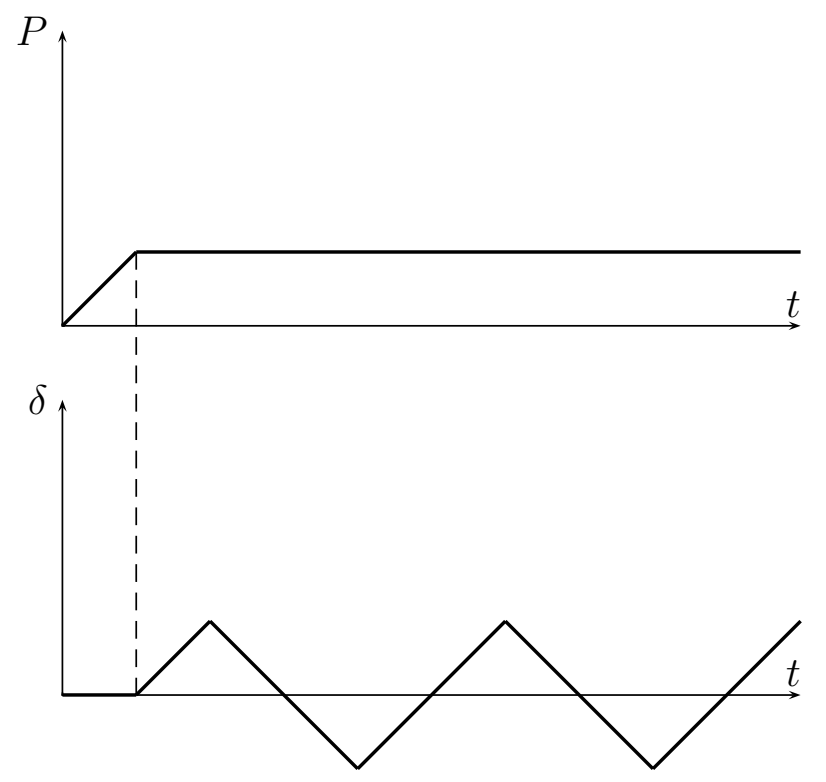

Figure 11. Boundary conditions: load and displacement amplitude evolution. 


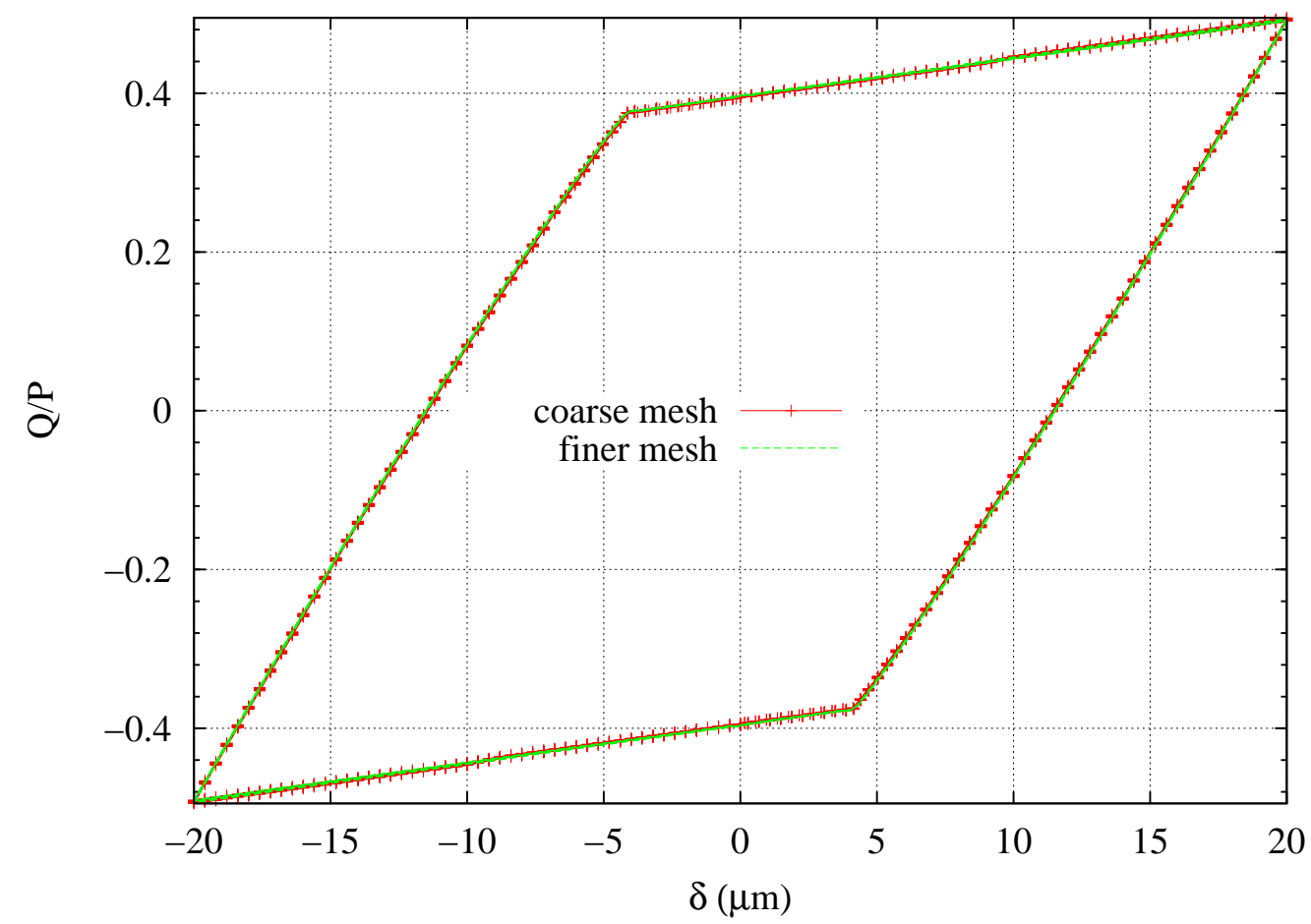

Figure 12. Comparison between the cycles obtained by the fine mesh and the coarse mesh. 


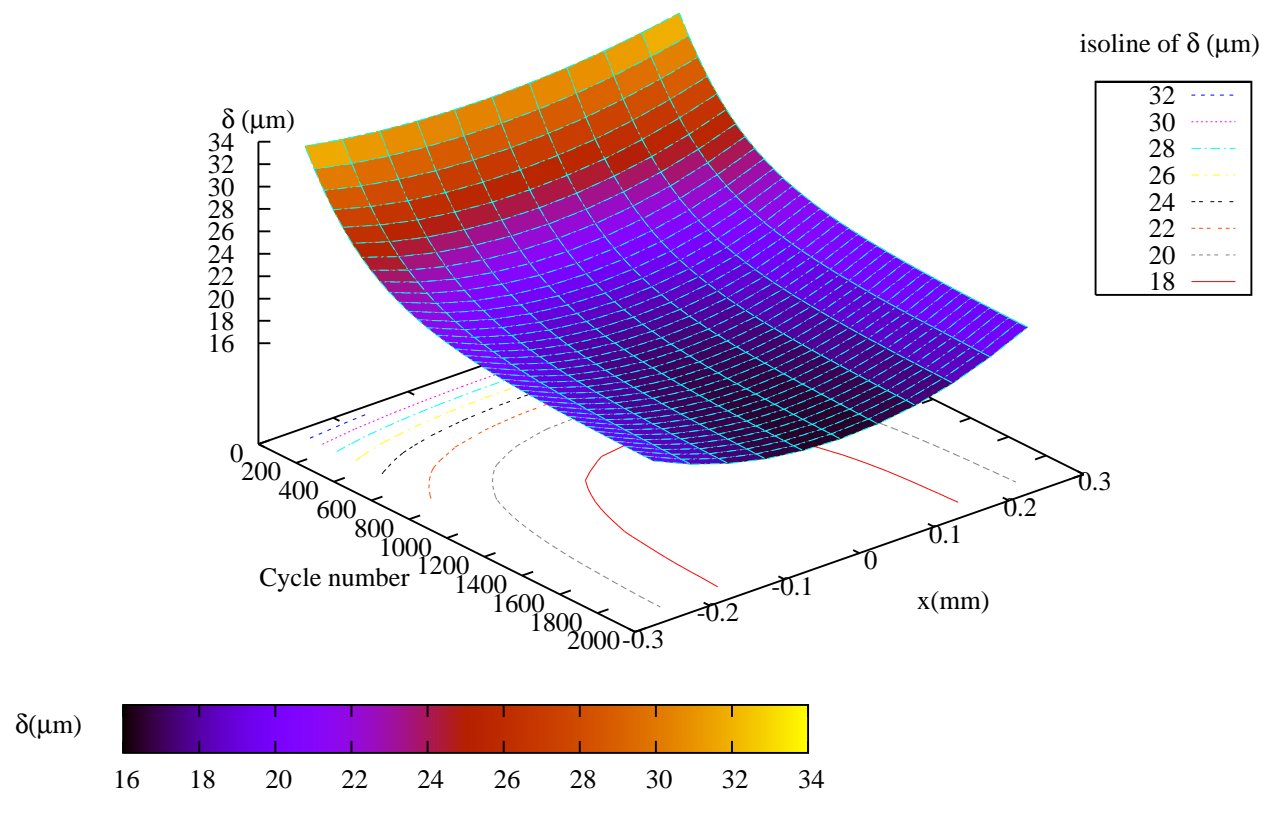

Figure 13. Evolution of the local slip $\delta$ function of the number of cycles and the position $x$ of the interface contact nodes. 

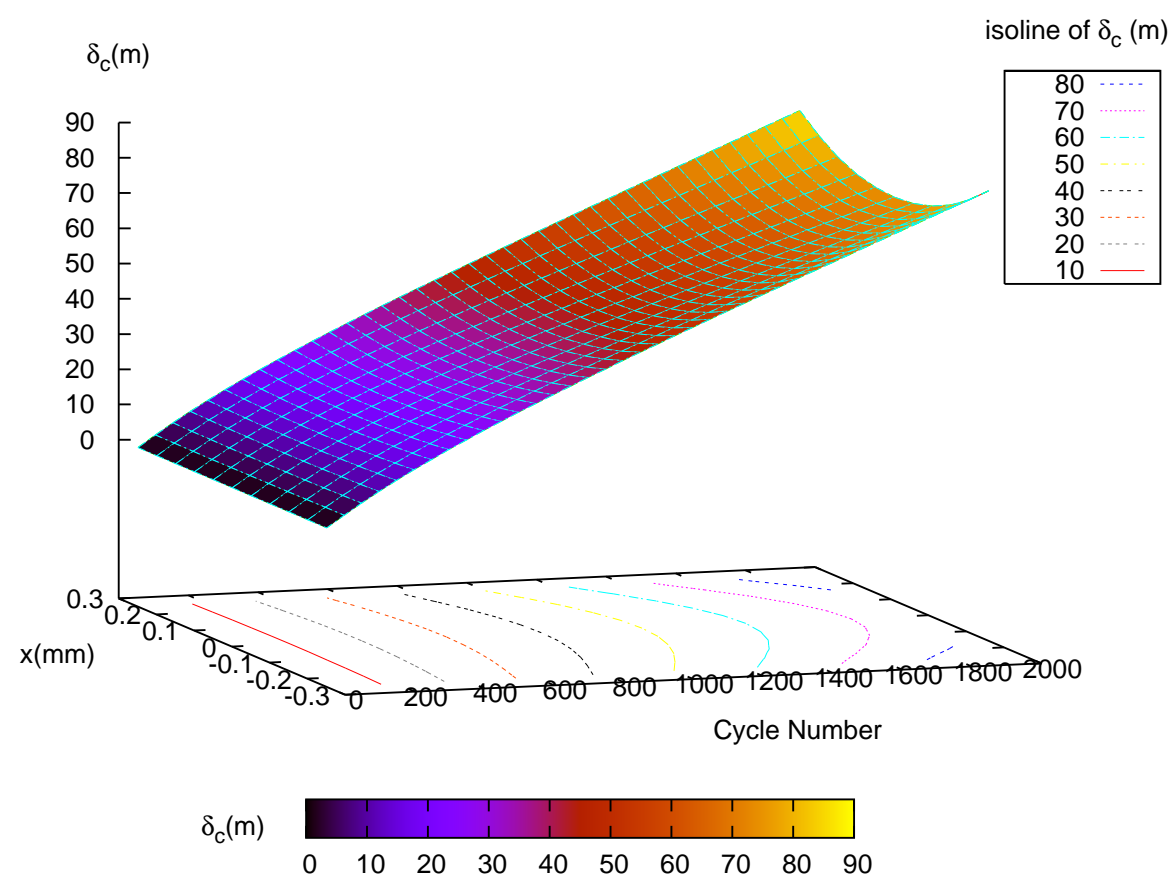

Figure 14. Evolution of the accumulated slip $\delta_{c}=\bar{\delta}$ function of the number of cycles and the position $x$ of the interface contact nodes. 


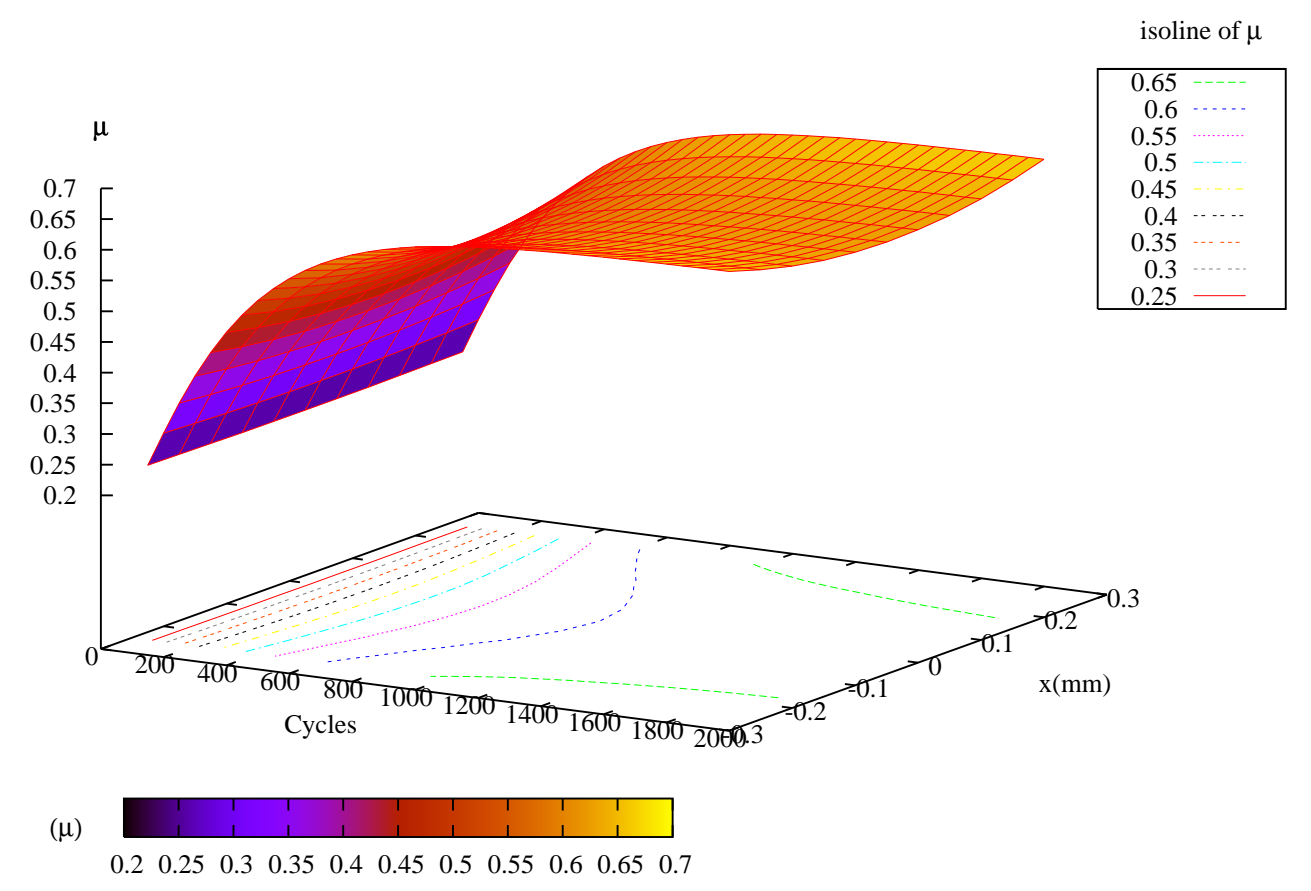

Figure 15. Evolution of the COF, function of the number of cycles and the position $x$ of the interface contact nodes. 

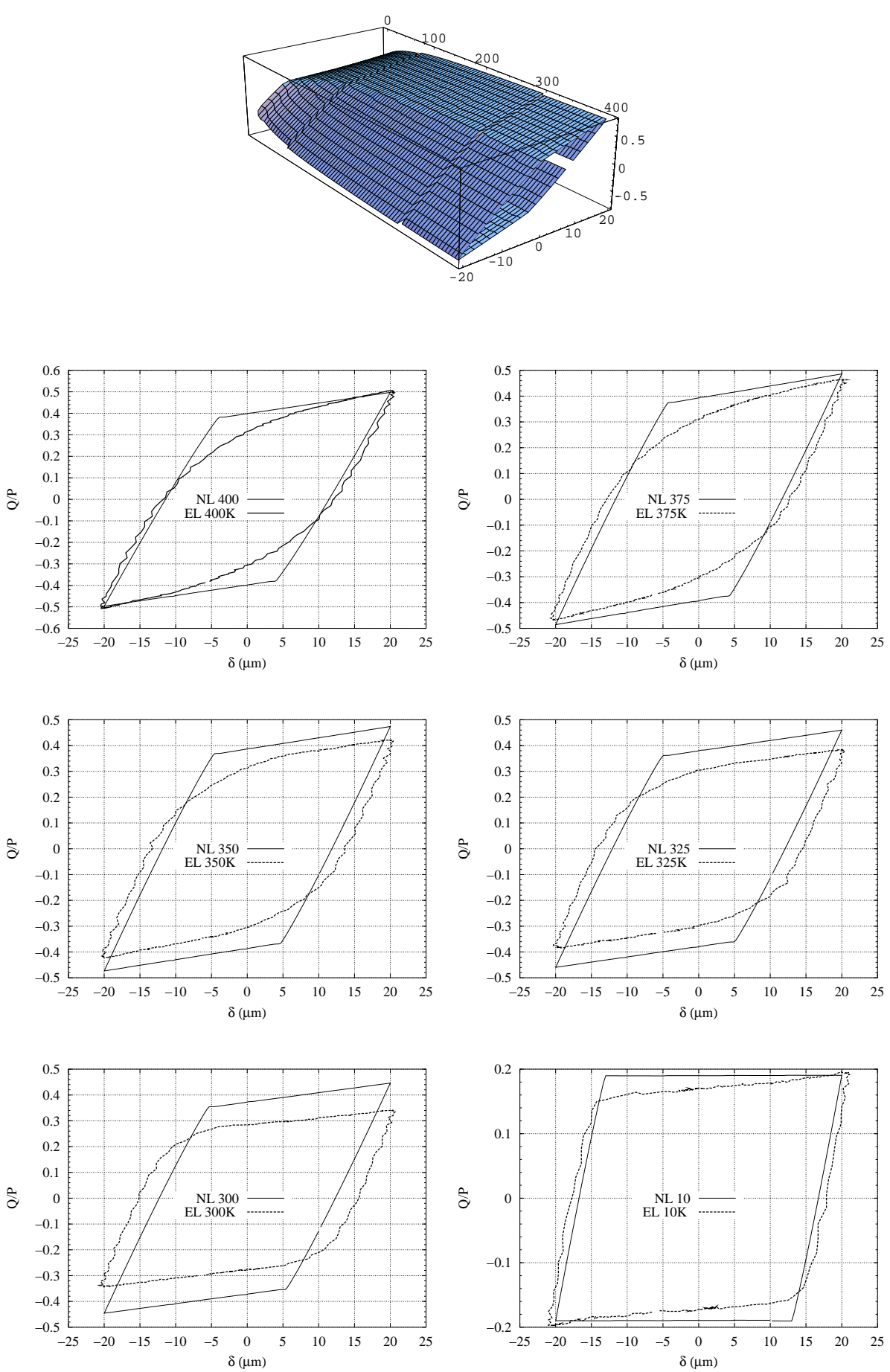

Figure 16. Numerical and experimental cycles evolution for $P=1000 \mathrm{~N}$ and $\delta^{*}=20 \mu \mathrm{m}$. 

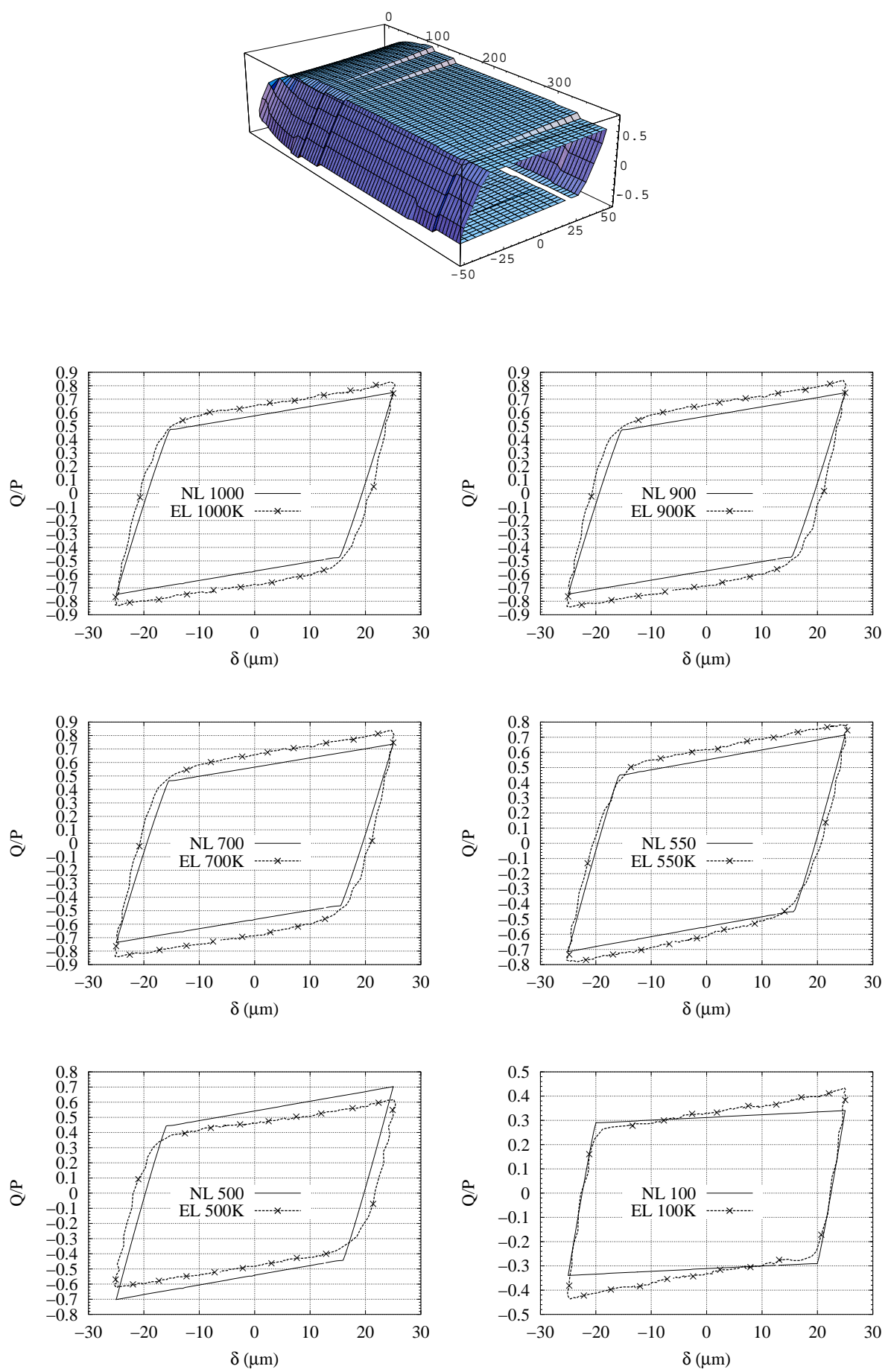

Figure 17. Numerical and experimental cycles evolution for $P=400 \mathrm{~N}$ and $\delta^{*}=25 \mu \mathrm{m}$. 

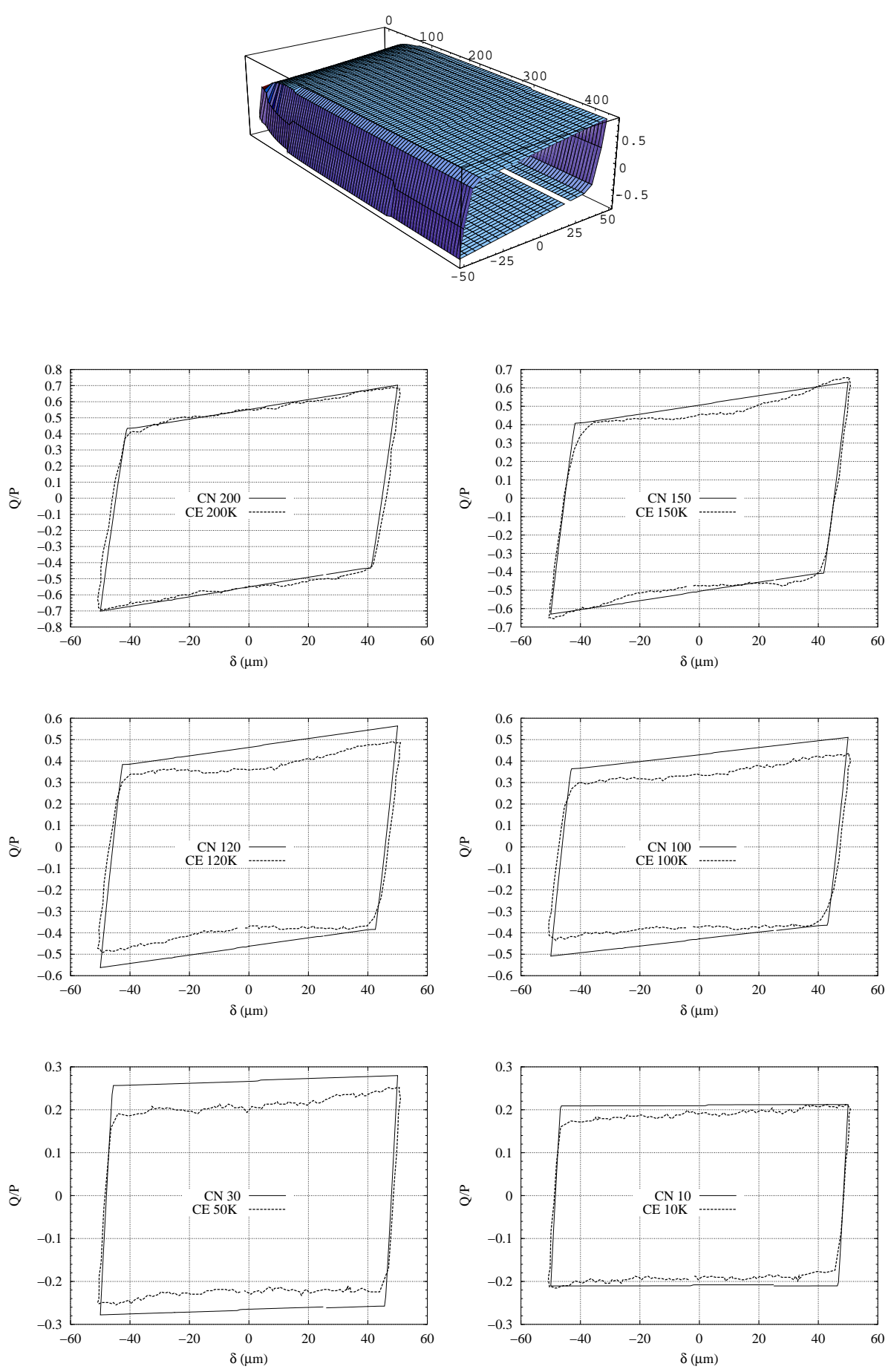

Figure 18. Numerical and experimental cycles evolution for $P=400 \mathrm{~N}$ and $\delta^{*}=50 \mu \mathrm{m}$. 